\title{
A 5 year retrospective study of emergency department use in Northwest Ontario: a measure of mental health and addictions needs
}

\author{
Cai-lei Matsumoto, $\mathrm{MPH}^{*}$; Terry $\mathrm{O}^{\prime}$ Driscoll, $\mathrm{MD}^{*}$; Jennifer Lawrance ${ }^{\ddagger \S}$; Andre Jakubow, MD ${ }^{\S}$; \\ Sharen Madden, $\mathrm{MD}^{\dagger}$; Len Kelly, $\mathrm{MD}^{\ddagger}$
}

\section{ABSTRACT}

Objective: The main objective of this study was to understand the five-year trend in total emergency department (ED) visits, frequency of use, and diagnoses and disposition of patients. Since the region has experienced a profound increase in opioid use disorder since 2009, we were particularly interested in changes in the volume of mental health and addiction (MHA) ED presentations.

Methods: Retrospective aggregate data analysis of ED visits to the Sioux Lookout Meno Ya Win Health Centre 2010-2014. Results: ED visit volume increased $29 \%$ over the five-year study period, while MHA ED visits increased $73 \%$. The admission rate remained stable at $6.9 \%$ of ED visits. Five-year trends in clinically grouped diagnostic categories identified respiratory, MHA, and abdominal/pelvic complaints as the three most common ED presentations. In 2014, MHA presentations accounted for $10.3 \%$ of ED visits, $8.7 \%$ of admissions, and $20.0 \%$ of inter-hospital transfers.

Conclusion: The dramatic increase in MHA ED visits mirrors the opioid epidemic the region is experiencing. MHA may soon become the commonest ED presentation. If reasons for ED visits serve as a proxy for unmet outpatient needs, increased efforts at developing community MHA services and addressing the related social determinants of health are required.

\section{RÉSUMÉ}

Objectif: L'étude décrite ici visait principalement à comprendre les tendances dégagées de statistiques recueillies sur une période de cinq ans quant au nombre total de consultations au service des urgences (SU), à la fréquence d'utilisation du service et des diagnostics ainsi qu'aux suites à donner. Compte tenu du fait que la région a connu une forte augmentation des problèmes liés à la consommation d'opioïdes depuis 2009, les changements quant au nombre de consultations au SU pour des troubles de santé mentale et de toxicomanie (SMT) intéressaient tout particulièrement les auteurs.
Méthode: II s'agit d'une analyse rétrospective de données agrégées sur les consultations médicales au SU du Sioux Lookout Meno Ya Win Health Centre, recueillies de 2010 à 2014. Résultats: Le nombre de consultations au SU a augmenté de $29 \%$ durant la période à l'étude, et le nombre de consultations au SU pour des troubles de SMT, lui, a augmenté de $73 \%$. Par contre, le taux d'hospitalisation est resté stable, à 6,9\% des consultations au SU. Les problèmes respiratoires, les troubles de SMT ainsi que les problèmes abdominaux ou pelviens se sont révélés les trois principaux groupes de diagnostics cliniques qui se sont dégagés des données recueillies sur la période de cinq ans. En 2014, les troubles de SMT représentaient 10,3\% des consultations au SU, 8,7 \% des hospitalisations et $20,0 \%$ des mutations interhospitalières.

Conclusions: L'augmentation considérable du nombre de consultations au SU pour des troubles de SMT reflète les proportions épidémiques que prend la consommation d'opioïdes dans la région. Les troubles de SMT pourraient bientôt devenir le principal motif de consultation au SU. Si les motifs de consultation au SU servent de déversoir de besoins non satisfaits parmi les patients externes, il faudra déployer davantage d'efforts pour mettre sur pied des services communautaires en santé mentale et en toxicomanie, et se pencher sur les déterminants sociaux connexes, liés à la santé.

Keywords: emergency, utilization, mental health, addiction

\section{INTRODUCTION}

Studies characterizing emergency department (ED) use have been largely confined to large urban centers. Rural ED use analysis is underrepresented in the literature, yet offers an interesting look at the fabric of medical services and the service needs in rural communities.

From the *Sioux Lookout First Nations Health Authority, Sioux Lookout, ON; †Division of Clinical Sciences, Northern Ontario School of Medicine, Sudbury, ON; ¥Sioux Lookout Meno Ya Win Health Centre, Sioux Lookout, ON; and §Emergency Department, Division of Clinical Sciences, Northern Ontario School of Medicine, Sudbury, ON.

Correspondence to: Len Kelly, P.O. Box 489, Sioux Lookout, ON, P8T 1A8; Email: Ikelly@mcmaster.ca 
In this study we examine the ED in a unique rural hospital setting in northwest Ontario which services a $385,000 \mathrm{~km}^{2}$ region, where patients are often triaged from remote First Nations community nursing stations before transfer to the hospital ED by air ambulance.

The Sioux Lookout Meno Ya Win Health Centre (SLMHC) is a 60 bed hospital serving 29,000 primarily First Nations patients across 31 remote communities. ${ }^{1}$

In 2009, regional First Nations leaders identified an "epidemic" of opioid abuse in their communities. ${ }^{2}$ In 2016, a state of emergency was declared concerning health status of the population, identifyinghealth inequities and wide gaps in services. ${ }^{3}$ Social determinants of health, such as housing and access to clean water, are common deficiencies in the First Nations communities of NW Ontario. ${ }^{4}$ Commentators describe underlying determinants of "colonialization, racism, social exclusion and lack of self-determination" as negatively affecting disparities in the health of Aboriginal peoples. ${ }^{5}$

In the context of these disparities, mental health and addiction (MHA) issues are significant concerns for the First Nations population in the SLMHC catchment area. First Nation youth experience significantly higher rates of mental health problems and have suicides rates six times the general population.,

The main objective of this study was to understand the five-year trend in total ED visits, and diagnoses and disposition of patients. Since the region has experienced a profound increase in opioid use disorder since 2009, we were particularly interested in the volume of MHA patients. $^{2,8}$

\section{METHODS}

Sioux Lookout Meno Ya Win Health Centre obtained anonymized data for a five-year period (2010-2014) from the Northwest Health Alliance, a health care data collection organization which accessed hospital utilization information from National Ambulatory Care Registration System (NACRS). Ethics approval was granted by Sioux Lookout Meno Ya Win Health Centre Research and Review and Ethics Committee.

Data analysis was completed using SPSS (Version 21, IBM, Armank, NY). Descriptive statistics were completed for sex, age, ED volume, disposition, and primary diagnosis. Diagnosis was completed using ICD-10 codes and grouped into relevant clinical categories. Mental health ICD-10 coded visits were combined with codes for substance abuse, addictions and self-harm ED visits.

\section{RESULTS}

From 2010-2014 there were 80,212 ED visits to SLMHC resulting in an annual average of 55 (95\% CI 50.2, 59.8) per 100 population. Fifty-four percent of visits were from Sioux Lookout while $41 \%$ were from Northern Communities and $5 \%$ were from areas outside of the catchment area. People aged 20-40 years made up the majority of visits with those aged 76 and older visiting the least. Women visited the ED more frequently than men: $55 \%$ versus $45 \%$ of visits.

The annual number of ED visits increased $29 \%$ from 2010-2014, for a total of 17,911 visits in 2014 (Figure 1). The annual visit rate per capita in 2014 was 62 per 100 population and averaged 55 per 100 over 5 years.

Admission rates were stable at 6.9\% (95\% CI 6.3, 7.5) (Figure 1) and less than 1\% of ED patients were transferred on to tertiary care centers.

The three commonest diagnostic ED visit categories were respiratory, MHA, and abdominal/pelvic complaints. Our most dramatic finding was the increasing trend in $\mathrm{ED}$ visits for MHA, which increased $73 \%$ in the 5-year study period (Figure 2).

The ED workload of MHAs incurred significant inpatient service needs, constituting $8.2 \%$ of admissions $(458 / 5,552)$ and $14.7 \%$ of transfers $(111 / 755)$ from 2010-2014.

In 2014 alone, MHA presentations in the ED accounted for $10.3 \%$ of ED visits and $8.7 \%$ of hospital admissions, and accounted for $20.0 \%$ of patient transfers to tertiary care centers or psychiatric facility (Table 1 ). MHA ED patients were most commonly $(59.2 \%)$ in the

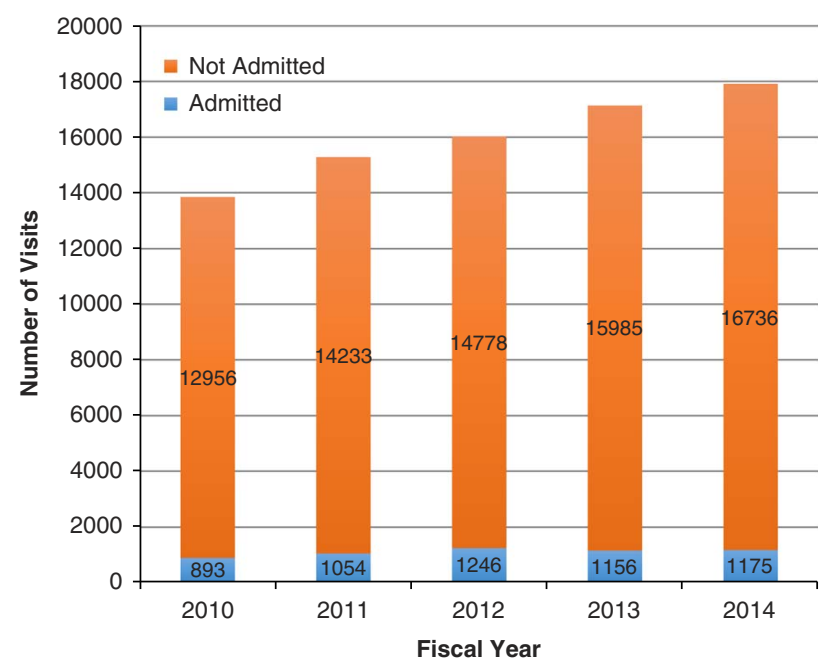

Figure 1. Yearly ED visits with disposition 2010-2014. 


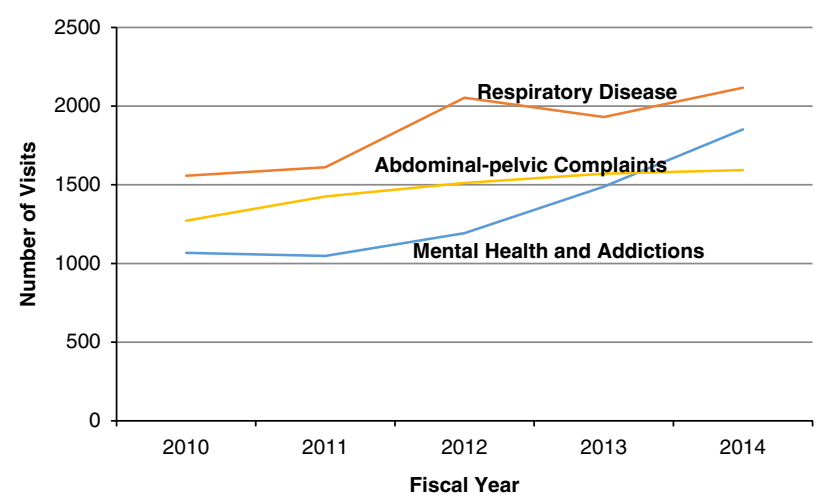

Figure 2. Three most frequent diagnoses at SLMHC ED 2010-2014.

\begin{tabular}{|c|c|c|c|}
\hline Diagnostic category & $\begin{array}{c}\text { ED Visits } \\
(\%)\end{array}$ & $\begin{array}{c}\text { Admissions } \\
\text { (\%) }\end{array}$ & $\begin{array}{c}\text { Transfers } \\
(\%)\end{array}$ \\
\hline Respiratory & $2117(11.8)$ & $182(15.3)$ & $3(2.6)$ \\
\hline $\begin{array}{l}\text { Abdominal/pelvic } \\
\text { complaints }\end{array}$ & 1594 (8.9) & $241(20.3)$ & $4(3.5)$ \\
\hline MHA & $1852(10.3)$ & $103(8.7)$ & $23(20)$ \\
\hline TOTAL & 17,911 & 1175 & 115 \\
\hline
\end{tabular}

20-40 age group and demonstrated a slight preponderance of females $(51.5 \%)$. This same age group also experienced the highest increase (90\%) in MHA ED visits during the study period.

\section{DISCUSSION}

Ontario-wide ED visits per capita increased $27 \%$ between 1998-2008, when it was measured at 42 per 100 population., ${ }^{9,10}$ This provincial utilization rate is slightly lower than the Canadian average ED utilization of 49 per 100 population. ${ }^{11}$ The SLMHC ED visit volume increased a similar rate $(29 \%)$ in just a 5 -year period, without related population increases.

Rural utilization rates are typically higher than urban, given that rural EDs provide both emergency and urgent primary care service. ${ }^{12,13}$

Our 2014 visit rate of 62 per 100 population (five-year average of 55), was lower than expected for such a large and remote region, and was lower than other rural estimates found in the literature ${ }^{14-17}$ (see Table 2). This likely reflects the geographic barrier of distance and access, as $80 \%$ of the catchment
Table 2. Estimated ED visits per capita in rural and general populations

\begin{tabular}{lc|}
\hline Location, yearr & $\begin{array}{c}\text { ED visits per } 100 \\
\text { population }\end{array}$ \\
\hline Ontario, $1977^{9}$ & 33 \\
Ontario, $2008^{10}$ & 42 \\
Canada, 2008 & 49 \\
Rural catchment areas & \\
Elliot Lake ON, 2001 & \\
Huron Country ON, 1998 & 98 \\
Sussex NB, 2009 & 89 \\
Exeter ON, 2003 & 84 \\
Sioux Lookout ON, 2010-2014 & 51 \\
average & 55 \\
\hline
\end{tabular}

Table 3. Mental health and addiction (MHA) ED visits per 100,000 population

Sioux Lookout Meno Ya Win Health Centre, 2014

Sioux Lookout Meno Ya Win Health Centre, 2012

Northwest Local Health Integration Network, 2012 ${ }^{34}$

Ontario, $2012^{34}$

population reside in remote communities without road access to the hospital EDs. Patients in these communities visit their local nursing station for urgent and emergent care and our hospital data only captured this information when they were triaged and transported to the hospital ED.

Respiratory disease was the most common diagnosis responsible for our ED visits. Canada-wide data from 2014 places respiratory illness as the third most frequent ED diagnosis (behind abdominal/pelvic pain and chest pain). ${ }^{18}$ Respiratory conditions are common in our catchment population.

We have previously documented high rates of admission for pneumonia for both infants and adults, likely a result of inadequate and crowded housing in northern communities. ${ }^{19-24}$

In general, respiratory and abdominal-pelvic complaints are common reasons for an ED visit, but MHAs are not in the national top ten common reasons for an ED visit. ${ }^{18}$ Our hospital encountered a twelve-fold higher rate of MHA ED visits in 2012 when compared to Ontario-wide numbers and the gap is widening (Table 3 ).

The leading reason for transfer from our facility was for orthopedic care (21.0\% of transfers). This was similar 
to a southern Ontario rural emergency department study, where $23 \%$ of transfers were orthopedic. ${ }^{15}$ However, our second leading reason for patient transfer $(20.0 \%)$ in 2014 was MHAs, while it accounted for only $4.5 \%$ of transfers in the southern Ontario study. ${ }^{15}$

Our ED visits for MHA diagnoses increased $73 \%$ in the 5-year study period (Figure 2). This increase was consistent with the growing epidemic of opioid abuse described by regional First Nations leaders in 2009. ${ }^{2}$ Opioid use disorder is additive to a preexisting burden of mental health challenges in the First Nations population. ${ }^{25}$ In 2013 , the regional maternity program documented $28 \%$ of pregnancies experiencing some narcotic exposure during gestation. ${ }^{26,27}$ One regional First Nation community documented an adult age adjusted rate of treatment for opioid use disorder of $41 \%{ }^{8}$ Many communities have begun to address addictions.

New community-based addiction treatment programs have been initiated in 22 of the 31 remote communities in the region and hospital-based services have developed to address with the burden of widespread opioid use disorder. ${ }^{3,28-32}$ The community-based programs play an important role in decreasing drug-related "medivacs". One community with a robust First Nations Healing and opioid agonist treatment program recorded a $30 \%$ decrease in such medical transfers. ${ }^{8}$ Positive community changes have resulted from one such community-based addiction treatment programming: school attendance has increased $33 \%$ and child protection cases have decreased by $58 \%{ }^{8}$

It may not be surprising that the regional visit rates to the ED for MHAs were orders of magnitude greater than the rest of the province (Table 3). ED visit rates for MHA include visits for intentional self-harm. Public Health Ontario statistics indicate our region has the highest rates of ED visits for self-harm in the province, particularly in youth (age 10-19). ${ }^{33}$

Increasing ED visits for mental health and addiction issues indicate that community-based and hospital MHA services need further development to address the scope of the problem. Substantial political, economic, and social changes are needed to address the social determinants of health which propagate an ongoing high burden of MHA issues in NW Ontario.

\section{Limitations}

Community nurses provide a substantial amount of primary and urgent care in the remote communities of our ED catchment area and this information is not captured in our study. The remote nursing stations and community MHA workers also locally manage a heavy workload related to MHAs, limiting transfers to the ED.

\section{CONCLUSION}

The Sioux Lookout ED provides rural hospital services in a unique hospital and community environment. The dramatic increase in MHA ED visits mirrors the opioid use disorder epidemic the region is presently experiencing. MHA may soon become the most common ED presentation. If reasons for ED visits serve as a proxy for unmet outpatient needs, increased efforts at developing community MHA services and addressing the underlying social determinants of health are required.

Competing Interests: None declared.

\section{REFERENCES}

1. Walker R, Cromarty H, Kelly L, et al. Achieving cultural safety in aboriginal health services: Implementation of a cross-cultural safety model in a Hospital Setting. Diversity in Health and Care 2009;6(1):11-22.

2. Nishnabe Aksi Nation. Resolution 09/92: prescription drug abuse state of emergency. Thunder Bay, ON. Available at: http://www.nan.on.ca/upload/documents/finance-2010-annualreport.pdf (accessed October 20, 2016).

3. NAN Resolution \# 15-23. Declaration of state of emergency in public health. Thunder Bay ON. Available at: http://www. nan.on.ca/upload/documents/comms-2016-02-24declarationhealth-emerg.pdf (accessed March 6, 2016).

4. Garrick R. Neskantaga issues call to action over living conditions. Wawatay News, May 15, 2014. Available at: http:// www.wawataynews.ca/community/neskantaga-issues-callaction-over-living-conditions (accessed October 20, 2016).

5. Allan B, Smylie J. (2015). First Peoples, second class treatment: The role of racism in the bealth and well-being of Indigenous peoples in Canada. Toronto, ON: The Wellesley Institute.

6. Library of Parliament of Canada 2014. Publication No. 201402-E. Current Issues in Mental Health in Canada: The Mental Health of First Nations and Inuit Communities. Available at: http://www.lop.parl.gc.ca/content/lop/Research Publications/2014-02-e.htm (accessed October 20, 2016).

7. Public Health Agency of Canada. The mental health and well-being of aboriginal peoples in Canada. Chapter 12. In: The Human Face of Mental Health and Mental Illness in Canada 2006. Available at: http://www.phac-aspc.gc.ca/publicat/ human-humain06/15-eng.php (accessed October 20, 2016).

8. Kanate D, Folk D, Cirone S, et al. Community-wide measures of wellness in a remote First Nations community experiencing opioid dependence: evaluating outpatient buprenorphinenaloxone substitution therapy in the context of a First Nations healing program. Can Fam Physician 2015;61(2):160-5. 
9. Ovens H, Chan B. Heavy users of emergency services: a population-based review. CMA7 2001;165:1049-50.

10. Auditor General of Ontario. Annual report 2010. Hospital emergency departments. Available at: http://www.auditor. on.ca/en/reports_en/en10/305en10.pdf (accessed December 13, 2015).

11. Canadian Institute for Health Information. Hospital Cost Drivers Technical Report; 2012. Available at: https://www. cihi.ca/en/hospital_costdriver_tech_en.pdf (accessed March 4, 2016).

12. Haggerty J, Roberge D, Pineault R. Features of primary healthcare clinics associated with patients' utilization of emergency rooms: urban-rural differences. Healthc Policy 2007;3(2):72-85.

13. McCusker J, Roberge D, Tousignant P, et al. Closer than you think: linking primary care to emergency department use in Quebec. St. Mary's Research Centre Report; 2013. Available at: http://www.aiiuq.qc.ca/images/articles/25.pdf.

14. Harris L, Bombin M, Chi F, et al. Use of the emergency room in Elliot Lake, a rural community of Northern Ontario, Canada. Rural and Remote Health 2004;4(1):240.

15. Rourke J, Kennard M. Emergency patient transfer from rural hospitals: a regional study. CFEM 2001;3(4):296-301.

16. Palmer E, Leblanc-Duchin D, Murray J, et al. Emergency department use. Can Fam Physician 2014;60(4):e223-9.

17. Vlabaki D, Milne W. Meeting Canadian Emergency Department Triage and Acuity Scale benchmarks in a rural emergency department. Can fु Rural Med 2009;14(3):101-4.

18. NACRS 2016. Available at: https://secure.cihi.ca/free products/NACRS-Infosheet_EDT_EN-web.pdf (accessed March 11, 2016).

19. McCuskee S, Fewer S, Kirlew M, et al. Bronchiolitis and pneumonia requiring hospitalization in young First Nations children in Northern Ontario. Pediatr Infect Dis 7 2014; 33(10):1023-6.

20. Poling J, Kelly L, Chan C, et al. Characteristics of hospitalized community acquired pneumonia in Northwestern Ontario. Can 7 Rural Med 2014;19(4):143-50.

21. Gordon J, Kirlew M, Bocking N, et al. Acute rheumatic fever cases in First Nations communities in North West Ontario: social determinants of health "bite the heart". Can Fam Physician 2015;61(10):881-6.

22. Kirlew M, Rea S, Muileboom J, et al. Invasive communityassociated methicillin resistant staphyloccus aureus: a two year prospective study. Can 7 Rural Med 2014;19(3):99-102.
23. Muileboom J, Hamilton M, Parent K, et al. Communityassociated methicillin-resistant Staphylococcus aureus in Northwest Ontario: A five-year report of incidence and antibiotic resistance. Can 7 Infect Dis Med Microbiol 2013; 24(2):e42-4.

24. Muileboom J, Hamilton M, Kelly L. The changing face of cellulitis and MRSA in rural Canada: a clinical update. Can $\mathcal{7}$ Rural Med 2013;18(4):137-9.

25. Health Canada (2015). First Nations \& Inuit health mental health and wellness. Available at: http://www.hc-sc. gc.ca/fniah-spnia/promotion/mental/index-eng.php (accessed March 10, 2016).

26. Kelly L, Dooley J, Cromarty H, et al. Narcotic-exposed neonates in a First Nations population in NW Ontario: incidence and implications. Can Fam Physician 2011;57(11): e441-7.

27. Dooley R, Dooley J, Antone I, et al. Narcotic tapering in pregnancy using long-acting morphine: an 18 month year prospective study in Northwest Ontario. Can Fam Physician 2015;61(2):e88-95.

28. Kiepek N, Hancock L, Toppozini D, et al. Facilitating medical withdrawal from opiates in rural Ontario. Rural Remote Health 2012;12:2193.

29. Kiepek N, Groom B, Toppozini D, et al. Evaluation of an inpatient medical withdrawal program in rural Ontario: a 1-year prospective study. Can $\mathcal{F}$ Rural Med 2015;20(3):92-7.

30. Dooley R, Dooley J, Antone I, et al. Narcotic tapering in pregnancy using long-acting morphine: An 18-month prospective cohort study in northwestern Ontario. Can Fam Physician 2015;61(2):e88-95.

31. Balfour-Boehm J, Rea S, Gordon J, et al. The evolving nature of narcotic use in northwestern Ontario. Can 7 Rural Med 2014;19(4):158-60.

32. Jiwa A, Kelly L, Pierre-Hansen N. Healing the community to heal the individual: Literature review of aboriginal community-based alcohol and substance abuse programs. Can Fam Physician 2008;54(7):1000.

33. Northwestern Health Unit Injury Trends Report. 2015, Available at: https://www.nwhu.on.ca/MediaPressCentre/ Documents/Report\%20on\%20injury\%20trends\%20-\%202015. pdf (accessed October 20, 2016).

34. Northwest LHIN. Demand capacity analysis for mental health and addiction services. 2014. Thunder Bay ON. Available at: http://www.northwestlhin.on.ca/resources/ ReportsPublications.aspx (accessed March 8, 2015). 